\title{
LOS IMAGINARIOS DE NACIÓN EN LA COYUNTURA DEL MOVIMIENTO DE TÚPAC AMARU II SIGLO XVIII Y SUS PROYECCIONES HOY
}

\author{
Jaime Ríos Burga \\ Universidad Ricardo Palma \\ jaimecultura@hotmail.com
}

\section{RESUMEN}

La ponencia reconstruye aspectos de los imaginarios de nación en la coyuntura del Movimiento de Túpac Amaru II como parte de la construcción nacional en el sistema mundo moderno colonial del siglo XVIII. Partimos de una ubicación histórica global, para luego centrarnos en su relación con los imaginarios de la nación-estado y estado nación presentes en la civilización occidental. Para finalmente, reconstruir sus especificidades en el movimiento anticolonial americano tupacamarista.

\section{PALABRAS CLAVE}

Túpac Amaru II / Imaginarios / Nación / Estado / Movimiento anticolonial.

\begin{abstract}
The paper reconstructs aspects of the imaginary of nation at the juncture of the Movement of Tupac Amaru II as part of nation building in the modern world of the eighteenth century colonial system. We start from a global historical location, and then focus on their relationship with the imaginary of the nation state and nation state present in Western civilization. To finally rebuild their specificities in the American tupacamarista anticolonial movement.
\end{abstract}

\section{KEYWORDS}

Tupac Amaru II / Imaginary / Nation / State / Anti-colonial movement. 
"Para Túpac Amaru II y como también él escribiera para todos mis compatriotas peruanos"

\section{UBICACIÓN HISTÓRICA}

La coyuntura del siglo XVIII fue una etapa de transición en que la incertidumbre, la confusión, el error, el fanatismo feroz y salvaje ${ }^{1}$ cobra fuerza en el campo social. El viejo paradigma civilizatorio del viejo imperio basado en la fe cristiana y la centralidad del Rey como monarquía absoluta vive una profunda crisis dando paso a la construcción de nuevos imaginarios de la modernidad. El imaginario de nación es uno de ellos. Se construye bajo el ideal de un espacio y organización colectiva homogénea o diversa como colectividad o Estado-nación. Expresan la transición del capitalismo comercial manufacturero al capitalismo industrial donde los imaginarios de nación expresan la heterogeneidad estructural y simbólica de la vida social.

La imaginación -como destaca Cornelius Castoriadis- cumple aquí un papel central, pues, afirma una función creativa/productiva en la consciencia/inconsciencia colectiva. Define la psique y la sociedad como polos irreductibles y demuestra que la monada psicológica original no puede por sí sola producir significación social. Estos no pueden ser deducidos de procesos racionales o naturales, pues la sociedad se instituye a sí misma de manera inconsciente y sin poder reconocerlo ${ }^{2}$.

En su sentido más profundo, el imaginario de nación se construye no como una representación de ningún objeto o sujeto esencial. Es producto de la incesante y esencialmente indeterminada creación socio-histórica y psíquica de figuras, formas e imágenes de actores colectivos concretos que proveen contenidos significativos y lo entretejen en las estructuras simbólicas. En nuestro caso arrastra las herencias de la civilización andina y del nombre del Perú, la sociedad colonial y postcolonial en sus relaciones sociales concretas. No se trata solo de contenidos reales o racionales que

1 ARRIGHI, Giovanni y SILVER, Beverly (1999), Caos y orden en el sistemamundo moderno, University of Minnesota Press, Akal.

2 CASTORIADIS, Cornelius (1983) La institución imaginaria de la sociedad. Barcelona:Tusquets. 
adquieren una vida autónoma sino también de contenidos presentes desde el inicio y que constituyen la historia misma ${ }^{3}$.

Los imaginarios de nación van por tanto más allá de las ideologías, se adentran a las estructuras profundas de las mentalidades de los actores individuales, grupos y clases sociales. Cumplen un lugar central en la constitución de la sociedad moderna entre la imaginación radical identificada como función creativa/productiva y el imaginario concebido como repertorio de las imágenes vigentes en la consciencia/inconsciencia colectiva.

Los imperios español y portugués entre otros, construyeron sistemas coloniales globales. El reino de los Austria entre los siglos XV-XVIII formó el reino de las Españas. Pero, fue en este último siglo con la transición y el advenimiento de la revolución industrial que se afirma el nuevo patrón de poder capitalista moderno colonial como cultura civilizatoria cristiana hegemónica bajo su forma de Estados nacionales donde, como destaca Quijano, la categoría raza en su continuidad histórica sigue siendo un elemento ordenador de las sociedades ${ }^{4}$.

Los movimientos nacionales anticoloniales del siglo XVIII cumplen así un papel crucial en la construcción del imaginario de la modernidad mundial. En sus estructuraciones de fuerzas, alianzas y oposiciones entre la colonialidad y la descolonialidad, continuidad y la ruptura, contienen imaginarios que van paralelos al desencuentro y encuentro entre la civilización

3 Para Mignolo basándose en Edouard Glissant el imaginario es la construcción simbólica mediante la cual una comunidad (racial, nacional, imperial, sexual, etc.) se define a sí misma. El término no tiene ni la acepción común de una imagen mental, ni tampoco el sentido más técnico, en el cual el imaginario forma una estructura de diferenciación con lo simbólico y lo real. Asume un sentido geopolítico como es el caso de la fundación y formación del imaginario del sistema mundo moderno/colonial. Véase: MIGNOLO, Walter. (2000), "La colonialidad a lo largo y lo ancho: el hemisferio occidental en el horizonte colonial de la modernidad", LANDER, Edgardo (Compilador), La colonialidad del saber: eurocentrismo y ciencias sociales, Perspectivas latinoamericanas, CLASO, Buenos Aires.

4 QUIJANO, Aníbal (2000) "Colonialidad del poder; eurocentrismo y América Latina", en La colonialidad del saber: eurocentrismo y ciencias sociales Perspectivas latinoamericanas. LANDER, Edgardo (Compilador). Buenos Aires: CLACSO-UNESCO. 
occidental y las otras civilizaciones del sistema mundo moderno/colonial ${ }^{5}$. Un mundo de imaginarios civilizatorios globales que contienen procesos sociales de dominación y liberación como actores. América y América Latina forman parte inseparable de este proceso histórico hasta nuestros días. Imaginarios que se presentan en campos definidos estructurando o desestructurando determinados patrones de poder como expresión de relaciones sociopolíticas materiales y simbólicas específicas.

Los imaginarios de nuestra modernización dependiente se construyen como parte inseparable de este proceso de la modernidad civilizatoria occidental. Un modelo más centralizado y diverso que el viejo patrón imperial de poder colonial español de la dinastía de los Austria pero en su centralidad marcado por la racialización del poder; la articulación política y geocultural del nuevo imperio hegemónico (léase Gran Bretaña); la distribución mundial del trabajo; el dominio y control de las relaciones de género, saberes y prácticas de las relaciones culturales e intersubjetivas; $y$, la dominación/explotación, colonialidad y corporeidad ${ }^{6}$. Teoría social que cada vez más cobra importancia como totalidad histórica para dar cuenta de nuestras sociedades en seis ámbitos básicos de reproducción: sexo, trabajo, subjetividad, autoridad, relación con la naturaleza y la comunicación como signo y significados ${ }^{7}$.

Eurocentrismo que se consolida a partir de la segunda mitad del siglo XVII con el desencuentro entre el civilizado occidental y el indígena

5 Con propiedad escribe Mignolo: "Ahora bien, la emergencia de ésta teoría política-se refiere a la occidental- dio lugar a otra: la teoría política descolonial. La teoría política descolonial, como es de suponer, no de los castellanos mismos, ni de los portugueses, sino de indígenas y africanos esclavizados y luego libertos, que reflexionaron sobre sus experiencias y la de su gente frente al tratamiento que recibieron de castellanos, portugueses, ingleses, franceses y holandeses. La teoría política descolonial es una teoría política que se apropia del lenguaje imperial (por ejemplo, la lengua castellana y la inglesa y el aparato conceptual de la teología cristiana). Esta teoría política opera en dos direcciones simultáneamente: una es el análisis de la sin razón de la razón cristiana y, la otra, la propuesta de principios éticos y formas de gobierno no basadas en la supuesta superioridad de la agencia europea". MIGNOLO, Walter y otros. (2009), La teoría política en la encrucijada descolonial, Ediciones Signo, Buenos Aires.

6 QUIJANO, Aníbal (2000) Colonialidad del poder y clasificación social, necesijournalof world-Systems research, vi, 2, summer/fall 2000, 342-386 Special Issue: Festchrift for Immanuel Wallerstein - Part I http://jwsr.ucr.edu .

7 QUIJANO (2010) Cátedra América Latina y la colonialidad del Poder. Lima. 
americano entre otras civilizaciones dominadas. Por tanto, responde a la imposición de las ideas del hombre civilizado occidental en nombre de la unidad del cosmos, la naturaleza y la sin razón de su vida ${ }^{8}$. Un consiente e inconsciente colectivo de dominación y liberación tan igual como las ideas de Dios, rey, diablo, bárbaro, indígena, ciudadano, mujer, hombre, Estado, partido político, capital, clase, tabú, etc. Todo un horizonte de sentido como cultura civilizatoria social global hegemónica.

Los imaginarios de Nación se desarrollan en un contexto sociohistórico donde la modernidad cultural civilizatoria occidental en sus desencuentros y encuentros con las otras culturas civilizatorias se presenta como la única totalidad histórica ${ }^{9}$ a seguir. Pues, en el marco del nuevo sistema moderno capitalista colonia ${ }^{10}$ manufacturero de los siglos XVIIXVIIII se sentaban las bases para la nueva etapa del capitalismo industrial. Dinámica decisiva para el destino del proceso de construcciones de las modernidades nacionales en Europa y el resto del mundo.

El nuevo colonialismo se impone como imaginario imperial hegemónico bajo la lógica del mercado manufacturero y ya no solo por medio de la dominación económica comercial y/o político-militar del territorio como fue la administración colonial y la cristianización. Los imaginarios de los no civilizados (indígenas) son destruidos, sometidos o perseguidos. El imaginario del viejo poder colonial imperial metropolitano "español" es reformado por

8 BARTRA, Roger. (1996) El salvaje en el espejo. Barcelona: Ediciones Destino.

9 Tiene razón Quijano cuando postula que el concepto de totalidad tiene que comprenderse como una configuración social no metafísica, orgánica o sistémica sino como un campo de relaciones donde la heterogeneidad y la homogeneidad estructural y no estructural, continuidad/discontinuidad, marcan la dinámica de la vida social histórico mundial. QUIJANO: Cátedra América Latina y la colonialidad del Poder, Lima, 2010.

10 Al respecto señala Quijano: "Desde el punto de vista eurocéntrico, reciprocidad, esclavitud, servidumbre y producción mercantil independiente, son todas percibidas como una secuencia histórica previa a la mercantilización de la fuerza de trabajo. Son pre-capital. Y son consideradas no sólo como diferentes sino como radicalmente incompatibles con el capital. El hecho es, sin embargo, que en América ellas no emergieron en una secuencia histórico lineal; ninguna de ellas fue una mera extensión de antiguas formas precapitalistas, ni fueron tampoco incompatibles con el capital" QUIJANO, Aníbal (2000) "Colonialidad del poder, eurocentrismo y América Latina" LANDER, Edgardo (Compilador) La colonialidad del saber: eurocentrismo y ciencias sociales, Perspectivas latinoamericanas. Buenos Aires: CLASO. 
la dinastía de los borbones propagando bajo el imaginario de la nación "española" a diferencia de la unidad de las "Españas" integrando los diferentes espacios bajo la dominación simbólica de Dios-Rey-Nación española-Colonia.

El imaginario eurocéntrico racionalista seculariza al sujeto como actor nacional como continuidad de la unidad de los súbditos. Pero, contradictoriamente para poder asumir un conocimiento que sea equivalente al ojo de Dios, se afirma la epistemología cartesiana encubriendo la corpo-política y la geo-política del conocimiento. No puede haber conocimiento universal mas allá de todo tiempo y espacio si el mismo estuviera localizado en un lugar y en un cuerpo determinado. De ahí que el dualismo cartesiano entre cuerpo y mente, mente y naturaleza, como dos substancias a parte le permite entonces representar la mente como fuera de toda determinación espacial y corporal y, por tanto, como capaz de producir un conocimiento no-situado, neutral y objetivo entendido como verdadero para todos en el universo ${ }^{11}$.

\section{CIVILIZACIÓNES E IMAGINARIOS NACIONALES EN EL SI- GLO XVIII}

El capitalismo occidental manufacturero e industrial bajo la cultura del hombre racional civilizado impone su hegemonía en el mundo. Un nuevo sistema donde el Estado nación cumple una función política centralizadora clave basada en el conocimiento institucionalizado de la cienciatécnica y la guerra.

Etapa donde los Estados Nacionales se vinculan entre sí mediante el intercambio de mercancías y flujos de capital en un mercado internacional cada vez más integrado. Un mercado mundial donde coexistían diferentes modos de producción (esclavista, feudal, pequeña y mediana producción mercantil, etc.) bajo la lógica hegemónica del capital manufacturero y capital bancario. Todo un sistema donde la lógica de la geografía de los espacios naturales cada vez más estaba condiciona por la lógica de los mercados internos y mercado mundial.

La idea de la unidad de la nación y del progreso encuentra aquí su desarrollo histórico como naturalización de las relaciones sociales. El

11 DUSSEL, Enrique (2000) "Europa, modernidad y eurocentrismo", LANDER, Edgardo (Compilador) La colonialidad del saber: eurocentrismo y ciencias sociales, Perspectivas latinoamericanas. Buenos Aires: CLASO. 
incivilizado tiene que seguir el camino de la nación civilizada occidental para convertirse en ser humano. La hegemonía occidental se establece así en el tiempo como poder material y simbólico de manera jerárquica: DiosRey-Siervo-Súbdito-Ciudadano nacional. El nuevo imperio "nacional" se apropia de los descubrimientos culturales, reprime toda resistencia y acultura al colonizado a su imagen y semejanza. El otro no tiene historia. Cada modelo nacional se considera creador y protagonista hegemónico de la modernidad. Pero la colonialidad en su materialidad, subjetividad e intersubjetividad origina desde su propio nacimiento actores que bajo diferentes formas de racionalidad resisten, subvierten o coexisten como expresión de movimientos nacionales anticoloniales.

Si ya Maquiavelo señalaba en El Príncipe: las ideas de soberanía, derecho internacional y secularización del poder bajo la hegemonía imperial del Rey o el príncipe debían predominar. Por tanto, la unidad nacional necesita de un soberano con poder absoluto para unir, armar y liberar la patria; separar el Estado de la iglesia o conquistar otros territorios para imponer su poder ${ }^{12}$. La idea de construir la nación estado u estado nación bajo los ideales de libertad, igualdad, fraternidad aparecía al decir Hans Morgenthau como un propósito trascendente que se debe defender y promover por todo el mundo buscando el establecimiento de la igualdad en libertad. Filosofía política que se consolida en el siglo XVIII en el imaginario social de la construcción nacional europea y la independencia americana: la independencia de Estados Unidos (1775-1783), la Revolución de Túpac Amaru II (1780), la Revolución Francesa (1789) y la Revolución Haitiana (1804).

La crisis del viejo modelo rentista comercial colonial daba paso al nacimiento del nuevo sistema capitalista moderno colonial. Ni España, ni Portugal a pesar de las reformas borbónicas del siglo XVIII pudieron hacer frente a la nueva dinámica del poder global del capitalismo manufacturero y luego industrial ${ }^{13}$. Los sistemas imperiales globales español y portugués no tuvieron la capacidad de incorporar a sus propias fuerzas internas y menos a los territorios coloniales a la nueva dinámica del capitalismo. La sobre explotación rentista y el desarrollo político administrativo colonial aceleró los movimientos anticoloniales en sus diferentes vertientes nacionales. Los Estados naciones en formación estimulan el desarrollo de sus burguesías

12 MAQUIAVELO (1963)

13 RÍOS BURGA, Jaime (1986) 
nacionales con una visión hegemónica global unida a la ética puritana y protestante. La austeridad -decía Adam Smith- es la causa inmediata del aumento del capital porque permite el ahorro y la acumulación ${ }^{14}$.

La hegemonía de Holanda, Bélgica y Gran Bretaña junto con los viejos imperios coloniales imponen un orden global bajo el dominio de Europa. Espacio que cobra cada vez más plena hegemonía directa o indirecta con respecto a los otros espacios civilizatorios. El poder hegemónico de Holanda se hace presente el siglo XVII bajo la idea de nación. Así mismo, Europa se consolida como hemisferio occidental bajo la idea del imaginario del Estado nación. La nueva colonialidad y colonialismo emergentes principalmente en Inglaterra, Francia, Bélgica y Alemania cobran fuerza a tal punto que como destaca Walter Mignolo la configuración de la modernidad en Europa y la colonialidad en el resto del mundo fue la imagen hegemónica sustentada en la colonialidad del poder, es decir, no puede haber habido modernidad sin colonialidad. La colonialidad es constitutiva de la modernidad ${ }^{15}$.

La palabra nación adquiere en este marco un carácter polisémico instrumental en la construcción de la modernidad mundo donde la tradición divina da paso a la secularización ilustrada de la razón como organización social. Un mundo social donde: "la idea de que los seres humanos pertenecen a un mundo gobernado por leyes naturales que la razón descubre y a las que ella también está sometida. Secularización, que implica la sustitución de Dios por la sociedad como principio de juicio moral. Y abre el camino al pueblo, la nación, en tanto cuerpo social que funciona también según leyes naturales y que debe desprenderse de formas de organización y de dominio irracionales, como las defensas corporativas o la legitimación del poder por revelación divina" ${ }^{16}$.

La transformación del imaginario de la mediación Rey-Súbditos por un imaginario de un cuerpo legislativo como representante de la "nación".

14 SMITH, Adam (1958)

15 MIGNOLO, Walter (2000), "La colonialidad a lo largo y lo ancho: el hemisferio occidental en el horizonte colonial de la modernidad", LANDER, Edgardo (Compilador) La colonialidad del saber: eurocentrismo y ciencias sociales, Perspectivas latinoamericanas. Buenos Aires: CLASO.

16 QUIJADA, MÓNICA (2006), Sobre "nación", "pueblo", "soberanía" y otros ejes de la modernidad en el mundo hispánico.http://digital.csic.es/bitstream/10261/9356/1/Quijada.pdf 
Una separación de las funciones e intereses donde la idea de una nación abstracta dominada absolutamente por el Rey abre camino a la nueva idea de construir una representación como expresión colectiva del pueblo nación. Una secularización divina del poder en diferentes modalidades nacionales que van entre la herencia monárquica centralizada Rey-súbditos y Rey-reinos. Momento histórico donde se oponen con fuerza la visión de la nación como construcción civilizatoria homogenizadora racista asociada a la idea de indisolubilidad de la "madre patria" y la construcción de un imaginario y visión social y nacional en la que conviven varias naciones.

Va tomando cuerpo la idea moderna de nación. Ya, en el Diccionario de Terreros y Pando de 1787 leemos sobre la palabra nación: "Nombre colectivo que significa algún pueblo grande. Reino, Estado, etc., sujeto a un mismo príncipe o gobierno. Esta omnipresente "sociedad" es una Junta de muchas personas en un mismo lugar para vivir en unión debajo de ciertas leyes y ayudarse mutuamente en sus necesidades"17.

Aquí ya la idea de nación cobra fuerza política movilizadora. Constatamos por ejemplo como Gran Bretaña, la potencia hegemónica, promueve decididamente los procesos de construcción nacional en oposición al pasado Modelo imperial monárquico "español" como testimonia la arenga de S. William Burke: "AMERICANOS: habiendo llegado el momento de que vuestro país se coloque entre las naciones independientes de la tierra, es necesario que conozcáis vuestros derechos..." 18

El destino de las naciones quedaba definido por su independencia, libertad y soberanía como leemos en la Declaración de Independencia de los Estado Unidos:

Nosotros los representantes de los Estados Unidos de América, reunidos en Congreso general, acudimos al juez supremo del mundo para hacerle testigo de la rectitud de nuestras intenciones. En el nomre y con el poder pleno del buen pueblo de estas colonias damos a conocer solemnemente y declaramos que estas colonias unidas son y por derecho han de ser Estados libres e independientes; que están exentas de todo deber de súbditos para con la Corona

17 QUIJADA, MÓNICA (2006), ibid.

18 ARTEAGA, Federico y GIMENEZ Carlos. Aporte crítico a la obra Venezuela, Fiesta, Imaginario político y Nación. http://fundacionburia. wordpress.com/aporte-critico-a-la-obra-venezuela-fiesta-imaginariopolitico-y-nacion/ 
británica y que queda completamente rota toda conexión política entre ellas y el Estado de la Gran Bretaña, y que, como Estados libres e independientes, poseen pleno poder para hacer la guerra, concertar la paz, anudar relaciones comerciales y todos los demás actos y cosas que los Estados independientes pueden hacer por derecho. Y para robustecimiento de esta declaración, confiados a la protección de la Providencia divina, empeñamos unos a otros nuestra vida, nuestra fortuna y nuestro sagrado honor. (Thomas Jefferson, Benjamin Franklin, John Adams ${ }^{19}$ ).

También en la Declaración de los derechos del hombre y del ciudadano del 26 de agosto de 1789 producto de la revolución francesa que en su introducción y parte III señala:

Los representantes del pueblo francés, constituidos en Asamblea nacional, considerando que la ignorancia, el olvido o el menosprecio de los derechos del hombre son las únicas causas de las calamidades públicas y de la corrupción de los gobiernos, han resuelto exponer, en una declaración solemne, los derechos naturales, inalienables y sagrados del hombre, a fin de que esta declaración, constantemente presente para todos los miembros del cuerpo social, les recuerde sin cesar sus derechos y sus deberes; a fin de que los actos del poder legislativo y del poder ejecutivo, al poder cotejarse a cada instante con la finalidad de toda institución política, sean más respetados y para que las reclamaciones de los ciudadanos, en adelante fundadas en principios simples e indiscutibles, redunden siempre en beneficio del mantenimiento de la Constitución y de la felicidad de todos.

En consecuencia, la Asamblea nacional reconoce y declara, en presencia del Ser Supremo y bajo sus auspicios, los siguientes derechos del hombre y del ciudadano:

La fuente de toda soberanía reside esencialmente en la Nación; ningún individuo ni ninguna corporación pueden ser revestidos de autoridad alguna que no emane directamente de ella. ${ }^{20}$

19 http://www.humanrights.com/es/what-are-human-rights/brief-history/ declaration-of-independence.html

20 http://es.wikipedia.org/wiki/Declaraci\%C3\%B3n_de_los_Derechos del Hombre y_del_Ciudadano 
Experiencias que en su especificidad anticolonial asumen una expresión de ruptura como el caso de Haití donde la extrapolación del bárbaro al civilizado occidental se hace presente en la Declaración de su independencia:

\section{Ciudadanos:}

No es suficiente con haber expulsado de nuestro país a los bárbaros que lo han ensangrentado hace dos siglos; nos es suficiente con haber frenado a las fracciones siempre renacientes que os presentaban sucesivamente el fantasma de la libertad que Francia exponía ante vuestros ojos. Se necesita un último acto de autoridad nacional: asegurar para siempre el imperio de la libertad en el país que nos vio nacer; arrebatar al gobierno inhumano, que mantiene desde hace tanto tiempo nuestros espíritus en la torpeza más humillante, toda esperanza de someternos. En fin, se debe vivir independiente o morir ${ }^{21}$

Transformaciones que en sus diversidades, sus herencias, sus cambios y sus continuidades asumen a su vez formas específicas en el espacio americano andino.

\section{LOS IMAGINARIOS DE NACIÓN EN LA COYUNTURA DEL MOVIMIENTO DE TÚPAC AMARU II EN PROSPECTIVA}

El imaginario de nación en nuestra experiencia histórica cobra fuerza ya bajo el impacto principal de las insurrecciones andinas ${ }^{22}$. Discurre primero bajo la idea organicista castellana de formar parte de la "madre patria" para luego construirse como imaginario de nación independiente. Nace así el indigenismo como expresión de resistencia cultural andina contra el poder del control y la dominación colonial. Un imaginario como afirmación de futuro que va delimitando una idea de territorio, sentimiento, psicología, identidad y cultura por construirse desde sus diversidades ${ }^{23}$. Como escribiera en su tiem-

${ }^{21}$ http://investigaciones.uniatlantico.edu.co/revistas/index.php/Historia_Caribe/ article/view/766/487

22 O'Phelan estima que entre 1720 y 1790 ocurrieron más de cien insurrecciones violentas contra el orden colonial, que involucraron a un gran número de campesinos andinos, dirigidos por castas y criollos disidentes. KLAREN, Peter. (2004), Nación y sociedad en la historia del Perú, Lima, IEP.

23 El indigenismo contemporáneo se nutre de toda esta herencia histórica de 
po Ciro Alegría: "El indigenismo es una afirmación del futuro y una fuerza que es inextinguible, como la afirmación de la parte indígena de la Nación"24.

Guamán Poma, en su racionalidad mítica utópica, aculturamiento y estrategia de poder imaginaba lo colectivo como integración de grupos diferentes subordinados al poder monárquico absolutista de España. Entre la diversidad del mundo andino y la hegemonía castellana muestra ya el dualismo psicológico y de mentalidad de coexistencia como "umilde bazallo" integrando el principio unificador del modelo inca y del modelo del reyno castellano. Pero desde sus diversidades, principalmente de su linaje o "nación" lucanas y soxas dice: Poma rrey de los animales, fue temido. Desde su nación fue segunda y su bizorrey de Tupa Ynga Yupanqui y casado con su hija lexituna, doña Juana Curi Ocllo. Con ello sirvió a Dios y a su majestad. Ayalla, fue leal Ayala, aci com leal y auallero de la casa de Ayala de España y de Biscaya, seruio a Dios y a su Majestad toda su uida hasta morir"25.

La palabra nación asume aquí el sentido castellano de lugar de nacimiento como identidad del grupo con su territorio parte a su vez "deste rreyno del Piru de la Yndias". Por tanto la "independencia" debía darse en la interrelación del rey Inca, del rey de los negros de Guinea, del Rey Moro y del rey cristiano, al servicio del Rey de Castilla "monarca del universo". Pero entre los mundos de arriba y de abajo esconde el retorno del orden primordial principalmente andino. Un retorno al pasado como anotaba Wachtel que prefiguaraba al mismo tiempo "un orden nuevo. Una esperanza casi mesiánica espera de la justicia del rey de España, asimilando al Inca, una última conmoción (Pachacuti) que pondrá del derecho este mundo que está al revés"26.

Garcilaso de la Vega desde su propio linaje étnico cusqueño construye su propio discurso nacional dirigiéndose a sus compatriotas "peruanos" el retorno del Inca. Como destacaba Alberto Flores Galindo:

revaloración de la cultura pre colombina cumpliendo toda una función en la formación de una de las tradiciones fundamentales de la formación y el desarrollo de la consciencia nacional.

24 ALEGRÍA, Ciro (1969) Primer encuentro de narradores peruanos. Lima: Casa de la Cultura del Perú. Lima.

25 GUAMAN POMA DE AYALA, Felipe (1980) Nueva Crónica y Buen Gobierno. Siglo XXI Editores, Tomo III, p. 1015.

26 WACHTEL, Nathan (1976) Los Vencidos. Los indios del Perú frente a la conquista española (1530-1570) Madrid: Alianza Editorial, p.320. 
La idea de un regreso del inca no apareció de manera espontánea en la cultura andina. No se trató de una respuesta mecánica a la dominación colonial. En la memoria, previamente, se reconstruyó el pasado andino y se lo transformó para convertirlo en una alternativa al presente. Este es un rasgo distintivo de la utopía andina. La ciudad ideal no queda fuera de la historia o remotamente al inicio de los tiempos. Por el contrario, es un acontecimiento histórico. Ha existido. Tiene un nombre: el Tahuantinsuyo. Unos gobernantes: los incas. Una capital: el Cusco. El contenido que guarda esta construcción ha sido cambiado para imaginar un reino sin hambre, sin explotación desorden y la obscuridad. Inca significa idea o principio ordenador ${ }^{27}$.

Bajo este imaginario hegemónico andino habla: "A los indios, mestizos y criollos. El Inca Garcilaso de la Vega, su hermano, compatriota y paisano", a "la gente común del Perú", es decir, el nombre del Perú asume ya un contenido colectivo: "Hablo de los del Perú, y no me entrometo en otras naciones, reinos o provincias que no conozco" 28 .

Túpac Amaru II recoge en su diversidad y unidad todas estas trayectorias de imaginarios nacionales creando desde su propia experiencia un modelo definido de construcción nacional donde la idea del "Inca Rey" como programa e idea fuerza busca orientar el movimiento social como un todo con el objetivo de organizar "a mis amados compatriotas de todas las calidades" en un cuerpo político centralizado:'Don Josep Gabriel Túpac Amaru Inca, de la Sangre Real y tronco principal en el que convoca a todos sus amados criollos americanos de todas las clases así españoles, como mestizos e indios que quisieran seguirlo"29.

Discurso que imagina una nación americana diversa que va entre la exaltación de la herencia del imperio Incaico y del mito del buen salvaje americano como bien lo expresa en el siglo XVIII Marmontel y Graffigny en oposición a las visiones nacionales homogenizantes eurocéntricas. Un imaginario de nación que en su unidad va vinculando lo mítico, lo mesiánico, lo milenarista y lo racional en los movimientos de base caciquil y campesina indígena andina colonial americana.

27 FLORES GALINDO, Alberto (1987) Buscando un Inca: Identidad y utopía en los andes. Lima: Instituto de Apoyo Agrario, p. 49.

28 GARCILASO DE LA VEGA, INCA (1986)

29 Colección Documental de la Independencia del Perú (CDIP) (1971), T.II, Vol. II, Lima, p. 256. 
El proyecto de Túpac Amaru II recoge todos estos elementos como parte de la construcción universal moderna del imaginario de nación. Anhela desde nuestras diversidades una sociedad política americana fruto primero de la reforma de la monarquía española y luego de la independencia colonial. Una nueva modalidad de construcción nacional donde ante la consolidación de la religión católica cristiana busca en la simultaneidad del cambio unir en las diferencias a todos los actores anticoloniales bajo las siguientes características:

1. La hegemonía política e ideológica del "Inca rey" asumiendo la idea judeo cristiana milenarista y mesiánica del Dios creador y la idea imperial del buen monarca. Pues: "los corregidores siendo bautizados desdicen el cristianismo con sus obras y más parecían ateístas, arrianos, calvinistas y luteranos porque son enemigos de Dios y del hombre ególatras del oro y de la plata" ${ }^{30}$.

2. Considerar los emblemas, la ideología y la práctica milenaria andina Inca como fuerza movilizadora en el movimiento social: “... vestido ya de las insignias reales que usaban los Incas diciéndoles que era llegado el tiempo en que debían sacudir el pasado yugo que por tantos años sufrían de los españoles y se les gravaba diariamente con nuevas pensiones y hostilidades que sus arbitrarios iban hasta ejecutar iguales castigos en todos los corregidores del Reyno, exterminar a todos los europeos y quitar repartimientos y aduanas y otras semejantes exacciones que a dictamen suyo desolaban el reino. Añadía que en nada contravenía a la obediencia del Rey; que resarcía los quebrantos que observaba en la fe católica pues ella era toda su veneración y el cuerpo eclesiástico su respecto que removidas las injusticias su único anhelo era conquistar la fe de los indios gentiles y retirarse después a gozar el fruto de sus expediciones; que no desmayasen en lo comenzado y lograsen su libertad que sí sabían que el amor que esto los manifestaba tendría por fin el perder la vida pero lo llevaría con gusto por dexar la gloria a su nación de verse restaurado su antiguo Estado"31.

3. Un lenguaje racional que mezclaba lo mítico y utópico de la peruanidad como parte del imaginario americano bajo la dirección de un gobierno autónomo que expresara la representación política de una Junta: "Don Josep Primero por gracias de Dios Inga Rey del Perú, Santa Fé, Quito, Chile, Buenos Aires y continentes de los mares del sur, Duque de la

30 CDIP (1981), T. I: 206-207.

31 CDIP (1971), T. II, Vol.: II: 225. 
Superlativa, Señor de los Cesares y Amazonas con dominio en el Gran Paititi, Comisario distribuidor de Piedad Divina. ... es acordado por mi consejo de junta, pródiga por repetidas ocasiones ya secreta ya pública que los Reyes de Castilla me han usurpado la corona y el dominio de mis gentes cerca de tres siglos" 32 .

4. Construcción que para cristalizarse tenía que crear desde las diferencias una unidad de conciencia anticolonial peruana y continental bajo una nueva empresa y poder autónomo, es decir, la unidad "americana de todas las clases". Por tanto, formar un solo cuerpo de nación donde en la continuidad del cambio histórico resaltan los conceptos de Nación india-Restitución-Independencia y Proyecto nacional continental americano ${ }^{33}$ : "Don Josep Gabriel Tupac Amaru Inga descendiente del último Rey y Señor Natural de esta reino del Perú y tronco principal en el por la gracia de Dios en cuanto la empresa en que estoy entendiendo para el mejor establecimiento y gobierno civil y político de ellos. Fue convocada la gente yndiana, mestizos y españoles - léase criollos o españoles americanos - de la provincia de Azángaro para que concurriese al efecto y habiéndolos ejecutado como eran obligados"34

5. Proyecto político que expresaba los intereses reales de construir la unidad económica nacional continental liberando a los actores de todo impuesto rentista integrando el mercado interno de una nación con los otros mercados internos de las otras naciones del continente: “... y demás gabelas que se inspecciona a las miserables puertas de los infelices vasallos de mí nación propagándola con inexorabilidad un segundo Pizarro en la tiranya que no solamente grava a mi nación extracción sino aun a las demás naciones y calidades... más si siguen los designios de mi saneada intensión que en consiguiendo la libertad absoluta de todo género de pensiones cargadas a mi nación el perdón general de mi apartada decisión al vasallaje que debo, y al total remolimiento de la casa de aduana" 35 .

CDIP (1971), T. II, Vol.: II: 578.

33 MATICORENA (1987), Prólogo al tercer tomo de la Colección Documental del Bicentenario de Túpac Amaru, Lima.

34 CDIP (1971), T. II, Vol.: II: 376.

35 CDIP (1971), T. II, Vol.: II: 378. 
1.Como también afirmar la idea de "patria" prolongando su sentido original de los nacidos en el "país" a un imaginario de la "patria americana". Visión integradora desde las diversidades como lo señala claramente el Bando escrito en Tinta el 7 de enero de 1781: "A mis amados compatriotas de cualquier calidad y condición que sean hago saber que deseando yo libertarlos de las opresiones en que se hallan cansados por corregidores, curas y otras personas" ${ }^{\prime 3}$.

Imaginario nacional que en su continuidad influyó afines de los siglos XVIII y XIX en lo económico, social, político ${ }^{37}$ y cultural ${ }^{38}$. Y, se integran a los nuevos discursos como del probabilismo; la independencia ${ }^{39}$, el pensamiento de Bravo de Lagunas, Victorino Montero, José Baquíjano y Carrillo, los redactores del Mercurio Peruano y el débil liberalismo de Villalta, Moreno, Larrea, Valdez. Ideologías que muestran la debilidad de la nueva ideología de la burguesía liberal en el espacio peruano producto del propio carácter colonial del poder.

Para concluir: ¿Qué queda hoy de toda esta experiencia de construcción nacional moderna del siglo XVIII?

La idea de nación como realidad e imaginario sirvió para autodefinirse y definir a otros, es decir incluir e incluirse en la construcción colectiva desde diferentes grupos étnicos o un único grupo étnico. La coyuntura en análisis nos enseña que estuvieron presentes ambas modalidades, mediada incluso entre la reforma o creación de una monarquía nacional Inca y luego republicana. Pero, en las profundas brechas étnicas raciales y culturales

36 CDIPCRETA (1981), T.I:110.

37 Por ejemplo, el 6 de julio de 1816 en el Congreso de Tucumán aprueba crear una monarquía en América que se llamaría "Provincias Unidas de América" cuyo rey sería Juan Bautista Túpac Amaru, último hermano quien en 1824 publica su memoria titulada: El dilatado cautiverio bajo el gobierno español de Juan Bautista Túpac Amaru $5^{\circ}$ nieto del último emperador del Perú.

38 Véase nuestro estudio realizado con Tirso Aníbal Molinari (1990): Patria, nación y mesianismo inca, en las ideologías de los procesos anticoloniales en el Perú 1780-1814, Cuadernos de Historia, X, Universidad de Lima.

39 Escribe Juan Bautista Túpac Amaru a Simón Bolívar: "Don José Gabriel Tupamaro, mi tiempo y venerado hermano, mártir del imperio peruano, cuya sangre fue el riego que había preparado aquella tierra para fructificar los mejores frutos que el Gran Bolívar había de recoger con su mano valerosa y llena de mayor generosidad" Citado por MACHADO, Ramón. (2013), "El regreso del último Inca, en La Primera, Lima, Domingo 3 de Noviembre, p. 23 
como en los débiles procesos de integración de los mercados internos como de socialización nacional fue gestándose un sentimiento de ser peruanos y americanos tendencia que hoy se consolida contradictoriamente a pesar del impacto del imaginario global post nacional.

Si bien como anota en parte Huntington: "Los Estados-Nación seguirán siendo los actores más poderosos del panorama internacional, pero los principales conflictos de la política global ocurrirán entre naciones y grupos de naciones pertenecientes a diferentes civilizaciones. El choque de civilizaciones dominará la política global. Las fallas entre las civilizaciones serán los frentes de batalla del futuro" 40 estamos presentes ante nuevos procesos de construcción en los imaginarios colectivos.

Hoy las naciones con o sin Estado se transnacionalizan y transculturalizan. En sus espacios diversos entra en crisis la idea clásica del Estado nación y Estado nación hegemónico global que construyó la modernidad occidental a lo largo de los siglos XV al XX. Crisis que va paralela a los conceptos de nación económica, nación social, nación política y nación cultural. Los mercados internos nacionales se hacen globales. Los procesos de homogenización social se ven afectados por nuevas estructuraciones sociales. El Estado nación como sociedad política cerrada acelera su crisis transformando su carácter funcional de control global. La nación cultural en su unidad se hace más diversa.

La tercera revolución industrial del capitalismo a diferencia de las etapas anteriores construye nuevos imaginarios de mercados globales en diferentes contextos de adaptación, resistencia y/o cambio de las naciones y los Estados nacionales al sistema mundo. En este escenario los pueblos nación transculturales como comunidades reales e imaginadas van hoy más allá del imaginario nacional y continental americano. Vemos surgir nuevas naciones transculturales en una creciente individuación individualizada donde lo monocultural o multicultural nacional no bastan ya para comprender y explicar la complejidad de la vida social. Nuevos

40 De Samuel Huntington véase: Quiénes somos? Los desafíos a la identidad nacional estadounidense; El choque de civilizaciones y la reconfiguración del orden mundial; Soldier and the State: The Theory and Politics of Civil-Military Relations; The Third Wave: Democratization in the Late Twentieth Century; American Politics: The Promise of Disharmony; The Common Defense: Strategic Programs in National Politics; No Easy Choice: Political Participation in Developing,Countries; El orden político en las sociedades en cambio. 
agrupamientos y pueblos naciones que van más allá de los imaginarios del Estado-nación, Nación-estado y Estados multinacionales.

En el Perú de hoy están todas estas tendencias en un marco donde pierden influencia los pasados imaginarios de la construcción del Estado nación como parte de la Madre Patria; el Estado nación autónomo e independiente; El Estado nación como Estado nación continental; y el Estado nación como un Estado más de los Estados Unidos. Vemos surgir la tendencia de nación transcultural en un escenario mundial unificado por la transmisión en tiempo real de la información y las imágenes. Un mundo donde la fusión entre lo real y lo simbólico genera la apariencia de un mundo sin fronteras pero en realidad en la continuidad étnica, regional y nacional esconde el tránsito a un nuevo orden global acelerados por el cambio tecnológico y, al mismo tiempo, los marcos regulatorios y escenarios mediáticos resultantes del sistema de poder y la revolución informática ${ }^{41}$.

Los imaginarios de nación presentes en el Perú se insertan hoy en estructuras sociales más amplias bajo diferentes formas globales de acumulación, realización e institucionalización ${ }^{42}$ en un marco de creciente desruralización y urbanización, los crecientes costos sociales y empresariales, la democratización real del Perú como sociedad política como parte del sistema mundo ${ }^{43}$. La promesa nacional de la vida peruana sigue vigente en un contexto caracterizado por la soledad individual, el cambio climático, la nueva producción basada en la innovación del conocimiento, la crisis alimentaria, la inseguridad hídrica, la inseguridad energética, el posicionamiento de la renta estratégica ${ }^{44} \mathrm{y}$ la creciente corrupción política y social. Un mundo donde surgen nuevos procesos de desigualdad y exclusión, fragmentaciones e integraciones, una nueva polarización social, violencia y conflictos, envejecimiento de las poblaciones, el deterioro

41 FERRER, Aldo (1998) Hechos y ficciones de la globalización Argentina y el Mercosur en el sistema internacional. Buenos Aires: Fondo de Cultura Económica.

42 ROBINSON, William (2000) La globalización capitalista y la transnacionalización del Estado. hhp/www.rco.net/globalizacion

43 WALLERSTEIN, Immanuel (1997) "¿Cambio social? El cambio es eterno. Nada cambia jamás", Memoria 100, México, Imprenta de Juan Carlos S.A.

44 RIVERO, Oswaldo (2001) "Los desafíos globales del Perú" en la República, Lima. 
ambiental, el creciente abismo digital, la deshumanización de la vida, el mayor protagonismo de la mujer, el pluralismo cultural y digital y el dominio de los sistemas abstractos de unos humanos contra otros ${ }^{45}$.

Es aquí precisamente donde la existencia del Perú como nación transcultural única y diversa depende de su institucionalización global como sociedad política organizada del conocimiento. Una construcción que democratice la vida social transfiriendo el poder de lo económico a lo social en sus lazos de vida más profundos, peruanizando y universalizando al Perú como sociedad de vida. Pues, en un contexto donde el límite del crecimiento global agota y transforma cada vez más la vida, sólo podemos tener presente y futuro si organizadamente planteamos una política de equilibrio social y sustentable como parte de una política de sustentabilidad de la diversidad de la vida en el planeta ${ }^{46}$. Para ello, se hace fundamental redefinir la función exclusivamente privatista del Estado integrando las políticas redistributivas desde el mercado a la sociedad bajo un modelo productivo sustentable en marcos normativos democráticos.

Hoy en la presente transición intracivilizatoria y ante la crisis de la modernidad y sus promesas, los imaginarios siguen operando de manera global en el marco sistémico de la modernidad/colonialidad entre la concentración y la desconcentración del poder nacional y postnacional, pero bajo la lógica del alto conocimiento organizado. Por tanto, al Perú como nación sólo le cabe en el cambio sistémico global auto organizarse conscientemente a partir de un verdadero proyecto de sociedad global resolviendo en la universalidad del cambio desde la diversidad de sus actores los cada vez más complejos problemas comunes de la humanidad y problemas específicos bajo una cultura civilizatoria de vida.

45 BINDÉ, Jerome (1999) Diez tendencias del siglo XXI, http://unesdoc.unesco. org/images/001196

46 RIFKIN, Jeremy (2012) La tercera revolución industrial Cómo el poder lateral está transformando la energía, la economía y el mundo. Barcelona: Paidós. 


\section{REFERENCIAS BIBLIOGRÁFICAS}

AGUIRRE, M.

1995 Los días del futuro. La sociedad internacional en la era de la globalización. Barcelona: Icaria Antrazyt.

AMIN, Samir

1999 El capitalismo en la era de la globalización. Barcelona: Paidós.

ARRIGHI, Giovanni y SILVER, Beverly

1999 Caos y orden en el sistema-mundo moderno. University of Minnesota Press: Akal.

BARNET, R. y CAVANAGH

1994 Global Dreams. New York: Simon \& Shuster.

TORTOSA, J.

1993 Sociología del sistema mundial. Madrid: Tecnos.

BARTRA, Roger

1996 El salvaje en el espejo. Ediciones Destino: Barcelona.

BAUMAN, Zygmunt

1999 La globalización consecuencias humanas. Buenos Aires: Fondo de Cultura Económica.

BAUMAN, Zygmunt

1998 La globalización consecuencias humanas. México: Fondo de Cultura Económica.

BECK, Ulrich

2004 Poder y contrapoder en la era global La nueva economía política mundial. Barcelona: Paidós.

BECK, Ulrich.

1998 ¿Qué es la globalización?, Falacias del globalismo, respuestas a la globalización, Barcelona: Paidós.

BERGER, Peter y Samuel HUNTINGTON

2002 Globalizaciones múltiple La diversidad cultural en el mundo contemporáneo. Barcelona: Paidós. 
BORON, Atilio

1997 «La globalización, ¿fase superior del imperialismo?», en CHOMSKY y BORON, Atilio. (1999), «Pensamiento único y resignación política», en Aproximaciones a la Globalización, Caracas, Nueva Sociedad, № 163.

BRAUDEL, Fernand

1997 El Mediterráneo y el Mundo Mediterráneo en la época de Felipe II. México: Fondo de Cultura Económica.

BURGA, Manuel

1998 Nacimiento de una utopía Muerte y resurrección de los incas. Lima: Instituto de Apoyo Agrario.

CALCAGNO, Alfredo

1996 "Neoliberalismo y estrategias alternativas de desarrollo", en HAYA DE LA TORRE, Agustín. Ed. América Latina y la economía mundial, Los retos del desarrollo económico en el próximo siglo, Lima: Derrama Magisterial.

CARRADINI, Luisa

2005 Entrevista a Jaques Le Golf "Seguimos viviendo en la edad media", La Nación, Miércoles 12 de Octubre, Buenos Aires.

CASTELLS, Manuel

2002 Cultura y Sociedad del conocimiento: presente y perspectivas de futuro. Debates Culturales: UOC.

2002 La galaxia Internet, empresa/Sociedad. Barcelona: Plaza \& Janés.

1998 La era de la información, Economía, sociedad y cultura, Vol.1, 2, 3, Madrid: Alianza editorial.

CASTORIADIS, Cornelius

1983 La institución imaginaria de la sociedad. Tusquets: Barcelona.

CHOMSKY, Noam y DIETERICH

1997 La sociedad global. Buenos Aires: Liber/Arte, CBC.

DE RIVERO, Oswaldo

1998 Mito del desarrollo. Los países invisibles en el siglo XXI. Lima: Mosca Azul Editores. 
DUSSEL, Enrique

2000 "Europa, modernidad y eurocentrismo", LANDER, Edgardo (Compilador), La colonialidad del saber: eurocentrismo y ciencias sociales, Perspectivas latinoamericanas, Buenos Aires: CLASO,

FERRER, Aldo

1998 Hechos y ficciones de la globalización Argentina y el Mercosur en el sistema internacional. Buenos Aires: Fondo de Cultura Económica.

1996 Historia de la globalización. México: Fondo de Cultura Económica.

FLORES, Víctor y MARIÑA, Abelardo

2000 Crítica de la globalización. Dominación y liberación de nuestro tiempo. México: Fondo de Cultura Económica.

GARCÍA CANCLINI, Néstor

1998 "Globalizarnos o defender la identidad". Nueva Sociedad, 163, Venezuela.

1999 "Globalizarnos o defender la identidad". En Aproximaciones a la globalización, Nueva Sociedad, 163, Venezuela.

GERMANÁ

2010 "Cátedra América Latina y la colonialidad del Poder, El análisis de la colonialidad del poder como perspectiva de conocimiento". Lima.

GLOBAL URBAN COMPETITIVES, REPORT

2010 Academia China de Ciencias Sociales: http://books.google.com.pe

HARD, Michael y NEGRI, Antonio

2002 Imperio. Barcelona: Paidós.

HAYA DE LA TORRE, Víctor Raúl

1936 El antimperialismo y el APRA. Santiago de Chile: Editorial Ercilla.

HILFERDING, Rudolf

1963 El capital financiero. Tecnos: Barcelona.

IANNINI, Octavio

1999 Teorías de la Globalización. México: Siglo XXI Editores. 
IANNI, Octavio

1998 "La era del globalismo". Nueva Sociedad, 163, Venezuela.

KLAREN, Peter

2004 Nación y sociedad en la historia del Perú. Lima: Instituto de Estudios peruanos

LANDER, Edgardo

2000 "Ciencias Sociales: saberes coloniales y eurocéntricos" en LANDER, Edgardo (Compilador), La colonialidad del saber: eurocentrismo y ciencias sociales, Perspectivas latinoamericanas, CLASO, Buenos Aires.

MAQUIAVELO

1963 El Príncipe. Buenos Aires: Malinca Pocket.

MARIÁTEGUI, José Carlos

19737 ensayos de la realidad peruana. Lima: Biblioteca Amauta.

MESSNER, Dirk

2000 Desafios de la globalización. Lima: Friedrich Ebert Stiftung.

MIGNOLO, Walter y otros

2009 La teoría política en la encrucijada descolonial. Buenos Aires: Ediciones Signo.

MIGNOLO, Walter

2003 Historias locales/díselos globales. Madrid: Akal.

2000 "La colonialidad a lo largo y lo ancho: el hemisferio occidental en el horizonte colonial de la modernidad", LANDER, Edgardo (Compilador), La colonialidad del saber: eurocentrismo y ciencias sociales, Perspectivas latinoamericanas, Buenos Aires: CLASO,

\section{MORIN, Edgar}

2010 "Por un pensamiento del sur, Traducción”, Ana-Rosa Tealdo, Instituto Peruano de Pensamiento Complejo Edgar Morín-IPCEM, Lima-Perú. 
MORO, Tomas

1992 Utopía. Madrid: Alianza Editorial.

ORTIZ, Renato

1996 Otro territorio, ensayos sobre el mundo contemporáneo., Buenos Aires: Universidad Nacional de Quilmes.

QUIJANO, Aníbal

2010 "Cátedra América Latina y la colonialidad del Poder". Lima.

2000 "Colonialidad del poder; eurocentrismo y América Latina", en La colonialidad del saber: eurocentrismo y ciencias sociales Perspectivas latinoamericanas, LANDER, Edgardo (Compilador). Buenos Aires: CLACSO-UNESCO.

2000 Colonialidad del poder y clasificación social, necesijournalof worldSystems research, vi, 2, summer/fall 2000, 342-386 Special Issue: Festchrift for Immanuel Wallerstein - Part I http://jwsr.ucr.edu

1999 "Coloniality and Modernity/Rationalit"y, en THERBORN, Goran y otros, Globalizations and Modernities, Stockholm, FRN.

1997 "Colonialidad del poder, cultura y conocimiento en América Latina", Anuario Mariateguiano, IX/9, 113-121.

MARX, Carlos

1973 El capital. México: Fondo de Cultura Económica.

PETRAS, Jame

1995 Empire or Repúblic. New York: Routledge.

RIFKIN, Jeremy

2012 La tercera revolución industrial Cómo el poder lateral está transformando la energía, la economía y el mundo. Barcelona: Paidós.

RIOS BURGA, Jaime

2010 “Globalización y sociedad peruana” en MEJÍA, Julio (Ed.). Realidad Nacional Sociedad, Estado y Cultura en el Perú contemporáneo, PEB, Lima, Universidad Ricardo Palma, Editorial Universitaria.

2009 "Aníbal Quijano: Diálogo sobre la crisis y las ciencias sociales en América Latina", Sociológica, Revista del Colegio de Sociólogos del Perú, Año $1 \mathrm{~N}^{\circ}$ 1, Lima.

2000 "Globalización y crisis de paradigma. Hacia una teoría transcultural de la sociedad humana", en Filosofía Globalización y multicultura- 
lidad, Vol. I. Actas del VIII Congreso Nacional de Filosofía, Lima, UNMSM.

1998 "Actores y estructuras sociales en la globalización”, en Revista de Sociología, Vol. X, Lima, Universidad Nacional Mayor de San Marcos

1990 La formación de los mercados internos y el Estado nacional en el Perú, Tesis doctoral, Universidad Complutense de Madrid.

1986 Ciclos productivos en el espacio peruano colonial Siglos XVI-XIX. Lima: Ediciones Trabajo.

RIVERO, Oswaldo

2001 “Los desafios globales del Perú” en la República. Lima.

ROBINSON, Williem

1998 La globalización capitalista y la transnacionalización del Estado. Taller Universidad de Warwick.

ROSAS MOSCOSO, Fernando

2002 "Crisis e Historia: Algunas consideraciones sobre la economía europea occidental en los siglos XIV y XVII". En Sociedad y cambio en Occidente. Lima: Universidad de Lima.

2009 Perú y Europa: dos casos de historias conectadas (Siglos XVI y $X V I I I)$. Lima: Universidad Ricardo Palma, Editorial Universitaria.

SEN, Amartya

2000 Desarrollo y libertad. Barcelona: Planeta.

SMITH, Adam

1958 Investigación sobre la naturaleza y causas de la riqueza de las naciones. México: Fondo de Cultura Económica.

STIGLITZ, Joseph

200390 La semilla de la destrucción. Colombia: Taurus.

THOMPSON, Grahame

1997 "Globalization and the Possibilities for Domestic Economic Policy", Internationale Politik und Gessellschaft, $\mathrm{N}^{\circ} 2$, Bond. 
TOFFLER, A

1995 La creación de la nueva civilización. La política de la tercera ola. Barcelona: Plaza \& Janes Editores. S.A.

TOURAINE, Alain

1999 ¿Cómo salir del liberalismo?. Barcelona: Paidós.

WALLERSTEIN, Inmanuel

1997 "Conferencia Forum 2000: Inquietudes y esperanzas en el umbral del nuevo milenio", en Iniciativa Socialista, No 47, Praga.

1997 “Cambio social? El cambio es eterno. Nada cambia jamás”, Memoria 100, México, Imprenta de Juan Carlos S.A.

1996 The Age of Transition: Trajectory of the World-System, 1945.2025. Londres: Zed Press.

WEBER, Max

2003 La ética protestante y el espíritu del capitalismo. México: Fondo de Cultura Económica.

1984 Economía y sociedad. México: Fondo de Cultura Económica. 